\title{
Functional genomic screening reveals asparagine dependence as a metabolic vulnerability in sarcoma
}

Simone Hettmer, Aff1 Aff2

Corresponding Affiliation: Aff1

Anna C Schinzel, $\stackrel{\text { Aff3 }}{ }$

Daria Tchessalova, $\stackrel{\text { Aff1 }}{\text { }}$

Nigel Richards, $\stackrel{\text { Aff4 }}{\text { (1) }}$

William C Hahn,

Amy J Wagers, $\stackrel{\text { Aff1 }}{\text { A }}$

\begin{tabular}{|c|c|c|}
\hline \multicolumn{3}{|r|}{ ArticleInfo } \\
\hline ArticleID & : $:$ & $\mid 43$ \\
\hline ArticleDOI & $:$ & || 10.1186/2194-7791-2-S1-A3 \\
\hline ArticleCitationID & $: \|$ & A3 \\
\hline ArticleSequenceNumber & $\|:\|$ & || 3 \\
\hline ArticleCategory & $\|:\|$ & Meeting abstract \\
\hline ArticleFirstPage & $\|:\|$ & $\mid 1$ \\
\hline ArticleLastPage & $\|:\|$ & $\mid 2$ \\
\hline ArticleHistory & $\|:\|$ & 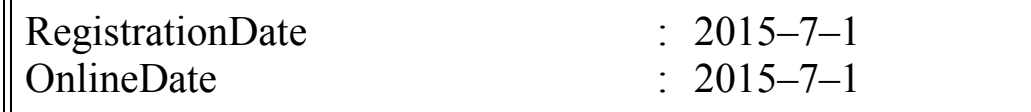 \\
\hline ArticleCopyright & $\|:\|$ & $\begin{array}{l}\text { Hettmer et al.2015 } \\
\text { This article is published under license to BioMed Central } \\
\text { Ltd. This is an Open Access article distributed under the } \\
\text { terms of the Creative Commons Attribution License } \\
\text { (http://creativecommons.org/licenses/by/4.0), which permits } \\
\text { unrestricted use, distribution, and reproduction in any } \\
\text { medium, provided the original work is properly cited. }\end{array}$ \\
\hline
\end{tabular}

Aff1

Howard Hughes Medical Institute, Department of Stem Cell and Regenerative Biology, Harvard Stem Cell Institute, and Joslin Diabetes Center, Harvard University, One Joslin Place, Boston, MA 02215, USA

Aff2

Zentrum fuer Kinder- und Jugendmedizin, Universitaet Freiburg, Mathildenstrasse 1, 79106 Freiburg, Germany

Aff3

Department of Medical Oncology, Dana-Farber Cancer Institute, Boston, MA 02115, USA 
Department of Chemistry and Chemical Biology, Indiana University - Purdue University Indianapolis, IN, USA

Abstracts of the 51st Workshop for Pediatric Research

51st Workshop for Pediatric Research

Göttingen, Germany

16-17 April 2015

This supplement has not been sponsored.

Meeting abstracts

\section{Aims}

Rhabdomyosarcomas (RMS) are mesodermal malignancies with skeletal muscle differentiation. The most common oncogenic mutations in RMS are in the RAS pathway. This study sought to identify actionable gene targets in sarcomas by selective targeting of the molecular networks that support the growth of Ras-driven sarcomas in mice.

\section{Methods}

Mouse RMS tumors were induced by expression of oncogenic Kras(G12v) and disruption of CDKN2A (p16p19) using ex-vivo transduction and intramuscular injection of transduced mouse satellite cells. These sarcomas identified a cluster of genes upregulated in mouse sarcomas and human RMS compared to normal skeletal muscle. A customized shRNA proliferation screen was used to screen this gene cluster for actionable transcripts that reduced sarcoma cell proliferation. Target gene effects on sarcoma growth were evaluated in mouse and human RMS cell lines and xenografts.

\section{Results}

Five immediately actionable proliferation-relevant gene targets were identified, and the anti-proliferative effects of 5 candidate chemicals, including asparaginase and amino sulfoximine (an inhibitor of asparagine synthetase, ASNS), were validated in mouse and human RMS cell lines. Silencing of ASNS, an amidotransferase that converts aspartate into asparagine, produced the strongest inhibitory effect on the growth of mouse Kras; p16p19 $9^{\text {null }}$ sarcomas. ASNS silencing in mouse and human sarcoma cell lines reduced the percentage of S phase cells and impeded new polypeptide synthesis. These effects of ASNS silencing were reversed by exogenous supplementation with asparagine. Finally, genetic silencing of ASNS in mouse sarcoma cells combined with depletion of plasma asparagine inhibited tumor growth in vivo.

\section{Conclusions}

The generation of new protein mass by rapidly proliferating sarcoma cells requires adequate Asparagine availability. Asparagine reliance of sarcoma cells may represent an actionable, metabolic vulnerability with potential anti-RMS therapeutic value. 